\title{
Does Exercise Intervention Improve Muscle Strength and Balance of Japanese Subjects with Osteoporosis?: a Systematic Review and Meta-analysis of Randomized Controlled Trials
}

\author{
Ryo Tanaka ${ }^{1) *}$, Junya Ozawa ${ }^{1)}$, Takuya Umehara ${ }^{2)}$, Nobuhiro Kito ${ }^{1)}$, \\ TAKAHIRO YAMASAKI ${ }^{1)}$, AYAKO ENAMI ${ }^{3)}$ \\ 1) Department of Integrated Rehabilitation, Hiroshima International University: 555-36, Gakuendai, \\ Kurose, Higashi-Hiroshima, Hiroshima 739-2695, Japan. \\ 2) Department of Rehabilitation, Saiseikai Kure Hospital \\ 3) Faculty of Medicine, Hiroshima University
}

\begin{abstract}
Purpose] The purpose of this study was to confirm the positive effect of exercise intervention on risk factors of falls for Japanese subjects with osteoporosis (OP). [Subjects and Methods] A systematic review and metaanalysis of randomized controlled trials were performed to investigate the effect of exercise on muscle strength and balance, which are risk factors of falls for Japanese subjects with OP. The electronic databases of PubMed, CENTRAL, PEDro, CINAHL, and Ichushi-Web were searched. In the process of systematic review and meta-analysis, the Preferred Reporting Items for Systematic Reviews and Meta-analyses Statement protocol (PRISMA) was used. [Results] Three studies (4 exercise groups) were included in our review. These studies used exercise interventions to improve handgrip, trunk extensor muscle strength, knee extensor muscle strength, static balance, and dynamic balance. Regardless of final measurement outcome, none of the studies showed that the exercise group had a better result than that of the control group in terms of muscle strength or balance. Synthesized data did not reveal a positive effect of exercise intervention on trunk extensor muscle strength. [Conclusion] Our results do not provide high-quality evidence that muscle strength and balance, which are risk factors for falls, are improved by exercise intervention for Japanese subjects with OP.

Key words: Osteoporosis, Exercise, Falls
\end{abstract}

(This article was submitted Oct. 11, 2012, and was accepted Nov. 20, 2012)

\section{INTRODUCTION}

In general, osteoporosis (OP) is recognized as a condition resulting in an increased risk of skeletal fracture due to a reduction in the density of bone tissue. OP most commonly manifests as fractures of the hip, vertebrae, and wrist. OP-related fractures are associated with high mortality and morbidity, chronic pain, reduction in quality of life, admission to long-term care, and increased health and social care costs ${ }^{1}$. Falls and fall-related risk factors contribute to fracture risk ${ }^{2}$. There is an inverse relationship between muscle strength and fall risk $^{3}$. Balance impairment is also an important risk factor of falls for elderly individu$\mathrm{als}^{4)}$. Since mobility impairments, such as reduced muscle strength and impaired balance, are risk factors of falls and fractures, exercise intervention for fall prevention should focus on improving balance and muscle strength ${ }^{3}$. An exercise program aimed at increasing strength and balance has been shown to be helpful, particularly as it can help reduce the risk of falls causing further fractures ${ }^{5)}$. However, the ev-

*To whom correspondence should be addressed.

E-mail: r-tanaka@hs.hirokoku-u.ac.jp idence for this was obtained from research trials conducted with US and European subjects. Few Japanese subjects with OP were included in that research article. Among the developed countries, Japan has the lowest level of obesity ${ }^{6}$, and it is widely accepted that body mass index (BMI) of Western people is greater than that of Japanese people. The load imposed by body weight on the trunk or lower limb muscles during exercise is higher for subjects with high BMI (overweight) than for those with low BMI (underweight). Additionally, culture, life style and dietary habit in Western countries are also different from Japan. Taking these differences into consideration, Japanese people with OP should not be expected to be identical to Western subjects with OP. For Japanese subjects with OP, Shirado et al. ${ }^{7}$ reported that trunk extensor muscle strength in an experimental group receiving an exercise intervention lasting for 12 months did not improve more than in a control group. Kanemaru and colleagues $^{8)}$ also showed the absence of effect of an exercise intervention lasting for 12 months on leg muscle strength and static and dynamic balance. Thus, evidence for the effect of exercise intervention on risk factors of falls may be poor for Japanese subjects with OP, and the response to exercise intervention for muscle strength or balance of Japanese with OP and low BMI may be different from that of 
Western people.

The purpose of our systematic review and meta-analysis was to confirm that exercise interventions are effective for Japanese subjects with OP, specifically for the improvement of muscle strength and balance, which are risk factors of falls.

\section{SUBJECTS AND METHODS}

In this study, the Preferred Reporting Items for Systematic Reviews and Meta-analyses Statement protocol (PRISMA) was used, and included randomized controlled trials (RCT) on the efficacy of exercise. These studies were not restricted by publication date or publication status. $\mathrm{Ob}$ servational studies including cohort studies were excluded. Our study sample included participants with an OP diagnosis. The selection of participants was not restricted to any particular age, sex, or body mass index (BMI) criteria. The trials that included individuals who had undergone surgery (e.g., vertebroplasty) or those who were scheduled to undergo surgery were excluded, because therapeutic exercise was not performed by these individuals. The trials that compared groups of Japanese OP subjects not performing exercises, with those performing muscle-strengthening exercise, aerobic exercise, stretching exercise, tai chi, or receiving manual therapy were selected. The inclusion criteria were not restricted by frequency, duration, or intensity of exercise. Muscle strength and balance were the primary outcome measures.

The electronic databases such as PubMed, the Cochrane Central Register of Controlled Trials (CENTRAL), the Physiotherapy Evidence Database (PEDro), the Cumulative Index to Nursing and Allied Health Literature (CINAHL), and Ichushi-Web (a Japanese medical literature database) were searched to identify studies from among those published until August 31, 2011. The searches were conducted by the first author (RT). The following search terms were used: "osteoporosis," "exercise," and "exercise therapy." The above-mentioned key search terms that comprised our search strategy were a combination of free text words and Medical Subject Headings (MeSH) terms. In the PubMed, CINAHL, and Ichushi-Web databases, we only searched for articles with a research design that was RCT. The systematic review process involved a peer review of the search strategies. The search was not restricted to any particular publication language. Table 1 shows the search strategy in detail.

The PEDro scale was used to determine the risk of bias in the studies ${ }^{9}$. The PEDro scale contains 10 items: random allocation, concealed allocation, baseline comparability, blind subjects, blind therapists, blind assessors, adequate follow-up, intention-to-treat analysis, between-group comparisons, and point estimates and variability.

Standardized mean difference (SMD) was used as the effect measure because the outcomes consisted of continuous data, which were standardized to the same scale. SMD is defined as the difference in mean outcomes between groups divided by the standard deviation (SD) of the outcome. The SMDs and corresponding 95\% confidence intervals (CI) were calculated for the continuous outcome data. Either a fixed-effect model or a random-effect model was applied on the basis of the examination of statistical heterogeneity between the trials.

In order to synthesize the results with the inverse variance method, Review Manager software version 5.1 (Copenhagen: The Nordic Cochrane Centre, The Cochrane Collaboration, 2011) was used. If SD were not provided in the study, the $95 \%$ CI or the standard error of the mean (SE) were converted into SD. Positive SD values are a sign that the exercise group showed greater improvement than the control group. Heterogeneity between trials was examined using the $\chi^{2}$ and $l^{2}$ tests. The $l^{2}$ test is not inherently dependent on the number of studies and is accompanied by an uncertainty interval. The following percent ranges may be considered as a rough guide for interpreting the findings ${ }^{10)}$ : $0 \%$ to $40 \%$, not important; $30 \%$ to $60 \%$, moderate heterogeneity; $50 \%$ to $90 \%$, substantial heterogeneity; and $75 \%$ to $100 \%$, considerable heterogeneity. A fixed-effects model was used in cases showing homogeneity and a random-effects model in cases showing heterogeneity.

\section{RESULTS}

The electronic database search yielded 373 citations. After discarding duplicates, 199 studies were considered. A further 196 were discarded because they did not meet the inclusion criteria. Finally, 3 studies ${ }^{7,8,11)}$ (4 exercise groups) were included in our review (Fig. 1).

The 3 studies included 190 participants (107 exercises and 83 comparisons) (Table 2). The average age of the patients ranged between 59 years ${ }^{7}$ ) and 74.7 years ${ }^{8)}$, and all the participants were women. The average height, body weight, and BMI of the patients ranged from $1.45 \mathrm{~m}^{8)}$ to $1.51 \mathrm{~m}^{11)}$,

Table 1. Search strategy

\begin{tabular}{ll}
\hline (1) PubMed & $\# 1$ osteoporosis [MeSH Terms] \\
& $\#$ 2 exercise [MeSH Terms] \\
& $\#$ 3 exercise therapy [MeSH Terms] \\
& $\# 4$ (\#1 AND (\#2 OR \#3)) \\
& Limits: Randomized Controlled Trial \\
(2) CENTRAL & $\# 1$ osteoporosis [MeSH Terms] \\
& $\#$ 2 exercise [MeSH Terms] \\
& $\# 3$ exercise therapy [MeSH Terms] \\
& $\# 4$ (\#1 AND (\#2 OR \#3)) \\
& 'Advance search \\
& Therapy: Strength training OR Fitness \\
& training OR Stretching, Mobilisation, \\
& Manipulation, Massage \\
& Title or Abstract: osteoporosis \\
& Method: clinical trial \\
& $\# 1$ osteoporosis [MeSH Terms] \\
& $\# 2$ exercise [MeSH Terms] \\
& $\# 3$ exercise therapy [MeSH Terms] \\
& $\# 4$ (\#1 AND (\#2 OR \#3)) \\
& Limits: Randomized Controlled Trial \\
\hline (4) CINAHL &
\end{tabular}


$48.7 \mathrm{~kg}^{8)}$ to $50.7 \mathrm{~kg}^{11)}$, and $22.2 \mathrm{~kg} / \mathrm{m}^{2}{ }^{11)}$ to $22.5 \mathrm{~kg} / \mathrm{m}^{2}$ ), respectively. The lumbar bone mineral density ranged from $0.681 \mathrm{~g} / \mathrm{cm}^{2}{ }^{11)}$ to $0.744 \mathrm{~g} / \mathrm{cm}^{2}{ }^{8)}$. Table 3 shows the characteristics of the interventions in each study. To improve muscle strength, participants in the 3 studies (4 exercise groups) performed balance exercises on one-leg ${ }^{7}$, back extensor strengthening exercises ${ }^{7,11)}$, and exercises to strengthen muscles of the upper and lower extremities ${ }^{8}$. To improve balance, the participants in one of the studies ${ }^{8)}$ performed upper and lower extremity-, abdominal muscle-, and back extensor muscle-strengthening exercises. The exercise duration in these studies ranged between $4^{11)}$ and 12 months $\mathrm{s}^{7,8)}$. The exercise frequency in two of these studies was 5 times

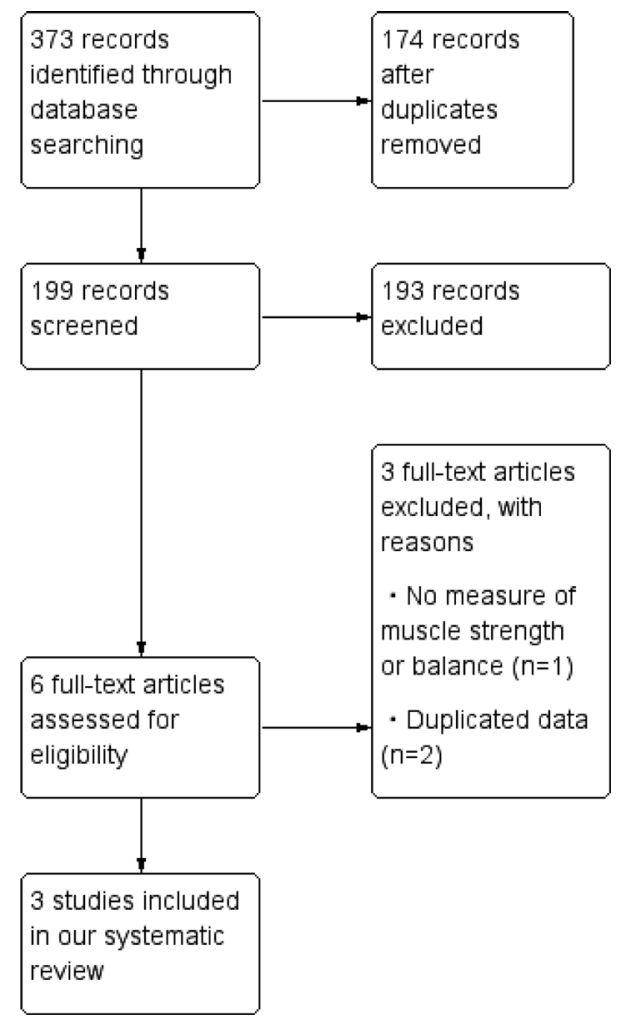

Fig. 1. Search and selection of randomized controlled trials (RCTs) per week ${ }^{7,11)}$. The exercise frequency was not reported in one of the studies ${ }^{8)}$. The control subjects in all the studies did not perform any exercise. Table 3 shows the outcomes measured in each study. Grip power ${ }^{8)}$, trunk extensor muscle strength $\left.{ }^{7}, 11\right)$, and knee extensor muscle strength ${ }^{8)}$ were measured. To measure balance, one-leg standing time and the timed up-and-go (TUG) test were used in one of the studies $^{8}$.

Table 4 shows a summary of the PEDro scores. The PEDro scores for the three studies were $4^{8)}, 5^{11)}$, and $6^{7}$. None of these studies concealed allocation or were blinded to subjects, therapist, or assessors.

Regardless of the final measurement outcome, none of the studies showed that the exercise group had a better result than that of the control group in terms of muscle strength or balance (Table 3). The data of the trunk extensor muscle strength from 2 studies $^{7,11)}$ (3 exercise groups) were obtained. The pooled SMD of the studies are illustrated using forest plots (Fig. 2). The pooled SMD of the studies that measured trunk extensor muscle strength $\left.{ }^{7}, 11\right)$ was not significant, and although moderate statistical heterogeneity was found, the findings were not statistically significant $\left(l^{2}\right.$ $=50 \%$ ).

\section{DISCUSSION}

The effect of exercise interventions on trunk extensor muscle strength, handgrip strength, knee extensor strength, one-leg standing time, and TUG were investigated in 3 studies (4 exercise groups) $)^{7,8,11)}$. As described below, the outcomes examined in our study could be considered significant fall-related fracture risk factors. Chien and colleagues ${ }^{12)}$ demonstrated that increased strength in the back muscles reduced the incidence of vertebral fractures in long-term follow-up studies. Albrand and colleagues ${ }^{3)}$ suggested that handgrip strength could predict the 5 year risk of fragility fractures. Stel and colleagues ${ }^{13)}$ identified leg extension strength as a treatable risk factor of recurrent falls. A Japanese study by Sakada and colleagues ${ }^{14)}$ revealed a significant difference in one-leg standing time between a fall group and a no-fall group. Zhu and colleagues ${ }^{15)}$ reported that TUG test performance was an independent risk factor of nonvertebral fracture, and they recommended it as a feasible, inexpensive physical performance assessment for

Table 2. Characteristics of participants

\begin{tabular}{|c|c|c|c|c|c|c|c|}
\hline Study & Population & Number & Age (years) & Height (m) & Weight $(\mathrm{kg})$ & BMI $\left(\mathrm{kg} / \mathrm{m}^{2}\right)$ & $\operatorname{BMD}\left(\mathrm{g} / \mathrm{cm}^{2}\right)$ \\
\hline \multirow{3}{*}{$\begin{array}{l}\text { Shirado et } \\
\text { al. (1998) }\end{array}$} & \multirow{3}{*}{$\begin{array}{l}\text { Osteoporotic } \\
\text { postmenopaus- } \\
\text { al women }\end{array}$} & $\mathrm{E} 1=14$ & 59 & (not reported) & (not reported) & (not reported) & $\mathrm{E} 1=0.697(0.050)$ \\
\hline & & $\mathrm{E} 2=14$ & & & & & $\mathrm{E} 2=0.673(0.081)$ \\
\hline & & $\mathrm{C}=13$ & & & & & $\mathrm{C}=0.737(0.065)$ \\
\hline \multirow{2}{*}{$\begin{array}{l}\text { Hongo et } \\
\text { al. (2007) }\end{array}$} & \multirow{2}{*}{$\begin{array}{l}\text { Osteoporotic } \\
\text { postmenopaus- } \\
\text { al women }\end{array}$} & $E=42$ & $E=67(5)$ & $\mathrm{E}=1.51(0.06)$ & $\mathrm{E}=50.7(5.7)$ & $E=22.2$ & $\mathrm{E}=0.681(0.080)$ \\
\hline & & $\mathrm{C}=38$ & $C=67(5)$ & $\mathrm{C}=1.51(0.05)$ & $\mathrm{C}=50.7(5.7)$ & $\mathrm{C}=22.0$ & $C=0.664(0.084)$ \\
\hline \multirow{2}{*}{$\begin{array}{l}\text { Kanemaru } \\
\text { et al. (2010) }\end{array}$} & \multirow{2}{*}{$\begin{array}{l}\text { Osteoporotic } \\
\text { women }\end{array}$} & $E=37$ & $E=74.7(6.7)$ & $\mathrm{E}=1.45(0.05)$ & $E=48.7(6.7)$ & $\mathrm{E}=22.5(3.2)$ & $\mathrm{E}=0.744(0.121)$ \\
\hline & & $\mathrm{C}=32$ & $\mathrm{C}=74.3(7.0)$ & $\mathrm{C}=1.48(0.05)$ & $\mathrm{C}=46.9(6.6)$ & $\mathrm{C}=21.5(2.7)$ & $\mathrm{C}=0.815(0.107)$ \\
\hline
\end{tabular}

BMI: Body Mass Index, BMD: Bone Mineral Density, E: Exercise group, C: Control group. One study includes multiple exercise, their groups are shown as E1, E2 in this table. ( ): SD 
screening patients for increased risk of fracture.

In a systematic review, de Kam and colleagues ${ }^{16)}$ suggested that muscle-strengthening exercises were effective at improving strength in the lower extremities and the back extensor muscles. Our review, however, identified no positive changes in muscle strength. The results of studies, ${ }^{7}$ 1) including trunk extensor muscle strength as their outcome were different from those of a previous study ${ }^{17}$ ). Gold and colleagues ${ }^{17)}$ confirmed the positive effect of various muscle strengthening exercises on trunk extensor muscle strength. They targeted the following muscles: trunk extensors, lower trapezius, middle trapezius, rhomboids, abdominals via stabilization, hip abductors, and hip extensors. In addition, to strengthen the trunk extensors, participants who could tolerate prone positioning (lying face down) performed trunk lifts against gravity in this position and progressed to holding small weights in their hands (up to $3 \mathrm{lbs}$ [1.36 kg] in each hand) as they performed the trunk lifts. Participants in two Japanese trials ${ }^{7,11)}$ performed back extensor muscle strengthening exercises without weights. A trial performed in Western countries ${ }^{18)}$, that confirmed the effect of muscle strengthening exercise on knee extensor muscle strength encouraged participants to increase the intensity of exercise if possible. On the other hand, in one of the Japanese trials ${ }^{8)}$ in our review, it was unclear whether progressive resistance exercise had been performed. The failure of exercise to af-

Table 3. Characteristics of intervention, outcome and results in individual studies in our review

\begin{tabular}{|c|c|c|c|c|c|}
\hline Study & Type of exercise & Duration & Frequency & $\begin{array}{l}\text { Relevant } \\
\text { outcome }\end{array}$ & $\begin{array}{l}\text { Results } \\
\text { (comparison between } \\
\text { groups) }\end{array}$ \\
\hline $\begin{array}{l}\text { Shirado et al. } \\
\text { (1998) }\end{array}$ & $\begin{array}{l}\text { E1: balance exercise with one leg } \\
\text { E2: balance exercise with one } \\
\text { leg, back extensor strengthening } \\
\text { exercise } \\
\text { C: no exercise }\end{array}$ & 12 months & $\begin{array}{l}\text { Balance exercise: } 30 \mathrm{sec} / \mathrm{set} \text {, } \\
\text { more than } 5 \text { times/day } \\
\text { Back extensor strengthening } \\
\text { exercise: } 20 \mathrm{~min} / \text { day }\end{array}$ & $\begin{array}{l}\text { Muscle } \\
\text { strength }\end{array}$ & $\begin{array}{l}\text { Trunk extensor muscle } \\
\text { strength: } \mathrm{E} 1=\mathrm{E} 2=\mathrm{C}\end{array}$ \\
\hline $\begin{array}{l}\text { Hongo et al. } \\
(2007)\end{array}$ & $\begin{array}{l}\text { E: back extensor strengthening } \\
\text { exercise } \\
\text { C: no exercise }\end{array}$ & 4 months & $\begin{array}{l}3 \text { to } 5 \mathrm{~min} / \mathrm{set} \\
1 \mathrm{set} / \text { day } \\
5 \text { times/week }\end{array}$ & $\begin{array}{l}\text { Muscle } \\
\text { strength }\end{array}$ & $\begin{array}{l}\text { Trunk extensor strength: } \\
\text { not reported }\end{array}$ \\
\hline $\begin{array}{l}\text { Kanemaru } \\
\text { et al. } \\
(2010)\end{array}$ & $\begin{array}{l}\text { E: the upper and the lower } \\
\text { extremities, the abdominal } \\
\text { muscles, and back extensor } \\
\text { muscles strengthening exercise } \\
\text { (instructed by physiotherapists) } \\
\text { C: no exercise }\end{array}$ & 12 months & Daily & $\begin{array}{l}\text { Muscle } \\
\text { strength } \\
\text { Balance }\end{array}$ & $\begin{array}{l}\text { Handgrip: not reported } \\
\text { Knee extensor: not } \\
\text { reported } \\
\text { Standing time on the leg: } \\
\text { not reported } \\
\text { TUG: not reported }\end{array}$ \\
\hline
\end{tabular}

BMD: Bone Mineral Density, TUG: Timed up-and-go test, E: Exercise group, C: Control group. One study includes multiple exercise, their groups are shown as E1, E2 in this table

Table 4. Risk of bias within studies

\begin{tabular}{lccccccccrrr}
\hline Study & 1 & 2 & 3 & 4 & 5 & 6 & 7 & 8 & 9 & 10 & Total \\
\hline $\begin{array}{l}\text { Shirado et al. } \\
\begin{array}{l}(1998) \\
\text { Hongo et al. }\end{array}\end{array}$ & Yes & No & Yes & No & No & No & Yes & Yes & Yes & Yes & 6 \\
$\begin{array}{l}\text { (2007) } \\
\text { Kanemaru et }\end{array}$ & Yes & No & Yes & No & No & No & Yes & No & Yes & Yes & 5 \\
\begin{tabular}{l} 
al. (2010) \\
\hline
\end{tabular}
\end{tabular}

PEDro Criteria: (1) Random allocation. (2) Allocation concealed. (3) Groups similar at baseline. (4) Participant blinding.

(5) Therapist blinding. (6) Assessor blinding. (7) Measures of at least one key outcome were obtained from $>85 \%$ of subjects. (8) Data were analysed by intention to treat. (9) Results reported for at least one key outcome. (10) Point measures and measures of variability provided

\begin{tabular}{|c|c|c|c|c|c|c|c|c|c|c|}
\hline \multirow[b]{2}{*}{ Study or Subgroup } & \multicolumn{3}{|c|}{ Exercise group } & \multicolumn{3}{|c|}{ Control group } & \multicolumn{2}{|c|}{ Std. Mean Difference } & \multirow{2}{*}{$\begin{array}{l}\text { Std. Mean Difference } \\
\text { IV, Random, } 95 \% \mathrm{CI}\end{array}$} & \\
\hline & Mean & SD & Total & Mean & SD & Total & Weight & IV, Random, 95\% Cl & & \\
\hline Hongo 2007 & 15.4 & 6.4 & 42 & 15.2 & 6.7 & 38 & $45.2 \%$ & $0.03[-0.41,0.47]$ & & \\
\hline Shirado 1998 & 398.3 & 100.2 & 14 & 450.9 & 97.5 & 13 & $27.5 \%$ & $-0.52[-1.29,0.25]$ & & \\
\hline Shirado 1998 & 513.1 & 102.5 & 14 & 450.9 & 97.5 & 13 & $27.3 \%$ & $0.60[-0.17,1.38]$ & - & \\
\hline Total $(95 \% \mathrm{Cl})$ & & & 70 & & & 64 & $100.0 \%$ & $0.04[-0.49,0.57]$ & & \\
\hline $\begin{array}{l}\text { Heterogeneity: } \mathrm{Tau}^{2}= \\
\text { Test for overall effect: }\end{array}$ & $\begin{array}{l}0.11 ; \mathrm{Ch} \\
z=0.13\end{array}$ & $\begin{array}{l}\mathrm{i}^{2}=4.03 \\
(\mathrm{P}=0.8\end{array}$ & $\begin{array}{l}3, \mathrm{df}=2 \\
39)\end{array}$ & $2(P=0$. & $13) ; I^{2}$ & $=50 \%$ & & & $\begin{array}{cccc}-4 & -2 & 0 & 2 \\
\text { Favor control group } & \text { Favor exe }\end{array}$ & $\begin{array}{l}4 \\
\text { group }\end{array}$ \\
\hline
\end{tabular}

Fig. 2 Forest plot for RCTs on the effect of exercise intervention on trunk extensor muscle strength 
fect muscle strength, as found in our review, may have been caused by poor choice of exercise and/or omission of exercise weights. The results of the study including handgrip as an outcome ${ }^{8)}$ were consistent with those of a previous study $^{14)}$.

In a systematic review of exercise interventions for balance impairment ${ }^{16)}$, most studies reported an improvement in balance with interventions involving balance exercises. In the present analysis, however, the effect of exercise intervention on balance was not positive. Madureira and colleagues ${ }^{19)}$ reported that an exercise intervention that included dynamic balance exercise (e.g., walking in the tandem position) and static balance exercise (e.g., standing on one leg) had a positive effect on balance. However, one of the reviewed studies with Japanese OP subjects ${ }^{8}$ used an intervention without balance exercise. It is likely that this difference in exercise content contributed to the lack of effect of exercise intervention on balance.

According to PRISMA ${ }^{20)}$, our systematic review and meta-analysis were performed correctly. However, our results should be interpreted cautiously. The included studies had a maximum PEDro score of 6. Blinding of the therapist and participants is not possible for this type of study, so 8 points is the highest possible score. Even when this factor is taken into consideration, however, the methodological quality of the studies was not high. The results of the systematic review of handgrip, knee extensor muscle strength, static balance, and dynamic balance were confirmed for one study only. The statistical heterogeneity of trunk extensor muscle strength might indicate inconsistency of the findings. Although the effect of exercise on trunk extensor muscle strength is considered to be dependent on demographic factors (e.g., age), our study did not confirm this finding. If the number of studies that examine the effect of exercise on these outcomes in Japanese subjects with OP were to increase in the future, a positive effect might be confirmed.

Although there is evidence of the effectiveness of exercise intervention for the prevention of falls in populations with OP, the effect of such interventions for Japanese subjects with OP has not been studied as extensively. As a result, most exercise recommendations for Japanese patients with OP are based on studies conducted in Western countries. However, the results of low-intensity or simple exercise may be poor for Japanese subjects with OP. Recommendations about exercise for the prevention of falls for Japanese populations should be made with caution. In addition, RCTs which investigated the number of falls after exercise interventions were not extracted in our review, and such these trials should be performed in the future.

\section{REFERENCES}

1) Papaioannou A, Morin S, Cheung AM, et al.: 2010 clinical practice guidelines for the diagnosis and management of osteoporosis in Canada: summary. CMAJ, 2010, 182: 1864-1873. [Medline] [CrossRef]
2) van Helden S, van Geel AC, Geusens PP, et al: Bone and fall-related fracture risks in women and men with a recent clinical fracture. J Bone Joint Surg Am, 2008, 90: 241-248. [Medline] [CrossRef]

3) Albrand G, Munoz F, Sornay-Rendu E, et al.: Independent predictors of all osteoporosis-related fractures in healthy postmenopausal women: the OFELY study. Bone, 2003, 32: 78-85. [Medline] [CrossRef]

4) Lajoie Y, Gallagher SP: Predicting falls within the elderly community: comparison of postural sway, reaction time, the Berg balance scale and the Activities-specific Balance Confidence (ABC) scale for comparing fallers and non-fallers. Arch Gerontol Geriatr, 2004, 38: 11-26. [Medline] [CrossRef]

5) Donald T, Ennis J, Mackenzie L, et al.: Management of osteoporosis: a national clinical guideline, (Scottish Intercollegiate Guidelines Network, 2003)

6) Murakami Y, Miura K, Ueshima H: Comparison of the trends and current status of obesity between Japan and other developed countries. Nihon Rinsho, 2009, 67: 245-252. [Medline]

7) Shirado O, Ito T, Kaneda K. The effect of exercise on postmenopausal osteoporosis. Bessatsu Seikeigeka, 1998, 33: 82-86 (in Japanese).

8) Kanemaru A, Arahata K, Ohta T: et al.: The efficacy of home-based muscle training for the elderly osteoporotic women: the effects of daily muscle training on quality of life (QoL). Arch Gerontol Geriatr, 2010, 51: 169-172. [Medline] [CrossRef]

9) Maher CG, Sherrington C, Herbert RD, et al.: Reliability of the PEDro scale for rating quality of randomized controlled trials. Phys Ther, 2003, 83: 713-721. [Medline]

10) Deeks JJ, Higgins JP, Altman DG: Analysing data and undertaking metaanalyses. In: Higgins JPT and Green S (eds): Cochrane Handbook for Systematic Reviews of Interventions. West Sussex: Wiley-Blackwell, 2008, pp 243-296.

11) Hongo M, Itoi E, Sinaki M, et al.: Effect of low-intensity back exercise on quality of life and back extensor strength in patients with osteoporosis: a randomized controlled trial. Osteoporos Int, 2007, 18: 1389-1395. [Medline] [CrossRef]

12) Chien MY, Yang RS, Tsauo JY: Home-based trunk-strengthening exercise for osteoporotic and osteopenic postmenopausal women without fracturea pilot study. Clin Rehabil, 2005, 19: 28-36. [Medline] [CrossRef]

13) Stel VS, Smit JH, Pluijm SM, et al.: Balance and mobility performance as treatable risk factors for recurrent falling in older persons. J Clin Epidemiol, 2003, 56: 659-668. [Medline] [CrossRef]

14) Sakada T, Doi M, Hosokawa T, et al.: Significance of measurement of time on one leg-standing in relation to the fall in elderly persons. The Journal of Saitama Kenou Rehabilitation, 2004, 4: 13-16.

15) Zhu K, Devine A, Lewis JR, et al.: 'Timed up and go' test and bone mineral density measurement for fracture prediction. Arch Intern Med, 2011, 171: 1655-1661. [Medline] [CrossRef]

16) de Kam D, Smulders E, Weerdesteyn V, et al.: Exercise interventions to reduce fall-related fractures and their risk factors in individuals with low bone density: a systematic review of randomized controlled trials. Osteoporos Int, 2009, 20: 2111-2125. [Medline] [CrossRef]

17) Gold DT, Shipp KM, Pieper CF, et al.: Group treatment improves trunk strength and psychological status in older women with vertebral fractures: results of a randomized, clinical trial. J Am Geriatr Soc, 2004, 52: 14711478. [Medline] [CrossRef]

18) Bergström I, Brinck J, Saaf M: Effects of physical training on bone minera density in fertile women with idiopathic osteoporosis. Clin Rheumatol, 2008, 27: 1035-1038. [Medline] [CrossRef]

19) Madureira MM, Takayama L, Gallinaro AL, et al.: Balance training program is highly effective in improving functional status and reducing the risk of falls in elderly women with osteoporosis: a randomized controlled trial. Osteoporos Int, 2007, 18: 419-425. [Medline] [CrossRef]

20) Liberati A, Altman DG, Tetzlaff J, et al.: The PRISMA statement for reporting systematic reviews and meta-analyses of studies that evaluate health care interventions: explanation and elaboration. PLoS Med, 2009, 6: e1000100. [Medline] [CrossRef] 